\title{
Conceptual Aspects of Time Perspective in the Emergency Situation
}

\author{
Ekaterina Karacheva \\ Lomonosov Moscow State University \\ E-mail: karacheva_k@list.ru \\ Olga Kvasova \\ Lomonosov Moscow State University \\ E-mail: 220163@mail.ru \\ Madrudin Magomed-Eminov \\ Lomonosov Moscow State University \\ E-mail: savindm2006@gmail.com \\ Olga Savina \\ Lomonosov Moscow State University \\ E-mail: savindm2006@gmail.com \\ Julia Horoshkova \\ Lomonosov Moscow State University \\ E-mail: akasta@inbox.ru
}

\section{Doi:10.5901/mjss.2015.v6n2s4p129}

\section{Abstract}

The basis of the article is the provision about two fundamental forms of conceptual intentionality developed in this theory: Land D-conceptual formations of personality and direction on the solution of boundary "tasks of life and "tasks for death" by a human in his daily and non-daily life worlds. It's very acute issue and it will be interested for those who are interested how to behave in emergency situation. The study was conducted in several stages. The methods themselves are directed in order to actualize the different conceptual intentions and direction on the past, present and future.

Keywords: time perspective; meaning structure of personality; L-ID-meaning structure; stress, personality; sense of meaning work personality; extreme situation.

\section{Introduction}

The topicality of the offered study is determined by the meaningfulness of the personality temporal perspective dynamics study in the emergency situation in connection with man-caused catastrophes, natural disaster, terror, violence in modern crisis state of the society generally. The notion of temporary perspective today is insufficiently developed and one-sides, and requires review of its linear interpretations (Kvassova, 2013; Gjesme, 1996; Nuttin, Lens, 1985). For the psychological solution of these problems we establish ourselves on the cultural-active theory, taking the conceptual intentionality of the personality life world for substantiation of the time procedure, at that the conceptual formations of personality indirectly act on the culturally stipulated time form and individual-specificity of personality time experience dynamics (Magomed-Eminov, 2006, 2009). We ground ourselves on the provision about two fundamental forms of conceptual intentionality developed in this theory: L- and D-conceptual formations of personality and direction on the solution of boundary "tasks of life and "tasks for death" by a human in his daily and non-daily life worlds. Transformation of the conceptual structure of life world is the main conceptual factor of emergency situation (Antonovsky, 1987; Herman, 1997; Janoff-Bulman, Frantz, 1997; Magomed-Eminov, 1997). This fundamental aspect is taken for establishment of the conceptual intentionality institutionalization. The relation between two types of conceptual direction can be interpreted 
from assimilation aspect, i.e. statement about that conceptual structures, independently from the conceptual contradictions, are assimilated into single dynamic structure, aspiring to the end of cognitive gestalt (Horowitz, 1986; Dalglaish, 2004). From the alternative point of view, two conceptual structures, institutionalized by life-oriented (L-senses) and death-oriented (D-senses), create non-assimilated, bifurcated structure, which corresponds to the existence of a human in the existential dichotomy of non-daily life world and forms bipolar L-D-conceptual system. This bifurcated structure serves the adaptation and growth of personality in the transordinary life situation.

Namely this mutual transition, executed in the personality work, and not by assimilation or deformation differently determines experience of time duration in the emergency situation.

This study has high practical value for the development of effective methods of psychological work in the sphere of time-management and psychological assistance provision to people in the emergency situation. The results obtained and basic conclusions of study are applied at creation of the psychological programmes to assist people, who suffered in the situations of emergencies, catastrophes, life circles, including that they were tested in the work Psychological service of the Union of Afghanistan Veterans, the Union of the Committees of Soldiers' Mothers, development and implementation of the educational programme of specialists preparation and Moscow State University in creation of the emergency psychology and psychological assistance department.

The emergency situation in literature is interpreted as the stressor (Selye, 1956; Lazarus, Folkman, 1984, Folkman, 2008), trauma, traumatic, emergency stress (Wilson, Krauss, 1985; Foa, Keane, Friedman, 2009; Contrada, Baum, 2010), Magomed-Eminov 2014.a).b), critical situation, difficult life situations, emergency situations and etc. We shall rely ourselves upon its interpretation as the situation of human experience feeling that goes beyond the limits of ordinary existence, in which the world conceptual structure is radically changed in connection with the death invasion in the life (Magomed-Eminov, 1997).

Considering transformation of personality time perspective in the emergency situation, we'll appeal to the emergency criteria (Magomed-Eminov, 2008): novelty, non-daily life and direction on transition; life-death existential dilemma; bipolarity " $L$ - D" of the personality conceptual structure; presence of threat and destruction, on the one part, and stability, courage and humaneness, on the other part; breach of life experience integrity, life peace fragmentation, necessity of temporal bounding of the life experience; transformation of self-identity in the emergency (Magomed-Eminov, 2007; Savina, 2012); unpredictability of events, uncertainty of the consequences, limitation of existence possibility, selfrealization, on the one part, and disclosure of possibilities inaccessible in daily life, on the other part; personality conceptual structure transformation; aspiration to the possibility of existence; care about personality existence; personality structure temporal transformation and its life peace; triad structure "disorder - adaptation - growth", or "suffering - steadiness - transgression" (Bonanno, et al., 2005; Kobasa, Maddi, Kahn, 1982; Seligman, Csikszentmihalyi, 2000; Tedeschi, Calhoun, 2004); disclosure of ethic-aesthetic measurement in human existence.

In the traditional approaches to the emergency situation, as a rule, positive transformation of time perspective, corresponding to adaptation of personality growth that doesn't allow revealing the whole spectre of differences in time perspective transformation interpreted in them as something distorted and defective in comparison with the daily world, is ignored (Gjesme, 1996; Kvassova, 2012; Zimbardo, Sword, 2012). Meanwhile, in our model it is supposed that time perspective transformation in the emergency situation is characterized by the institutionalization of more complete structure of time perspective due to overcoming and suppression of D-conceptual direction. Transformation of time perspective is explained by us from the aspect of specific forms of time perspective institutionalization in connection with the forms of conceptual intentionality.

\subsection{General hypothesis}

In the emergency situation of institutionalization of time perspective is done non-linearly, but on the basis of two plans; one plan of time perspective is institutionalized on the basis of conceptual intentionality, set by L-conceptual (life-centred) structures of the life world, and second plan - D-conceptual (death-centred) structures of life world (Magomed-Eminov, 1997, 1998, 2007, 2009).

\section{Research Methodology}

\subsection{Methods of study}

1) Modified variant of methods of uncompleted sentences by J. Nuttin (Nuttin, Lens, 1985), 2) questionnaire of posttraumatic R. Tedeschi, L. Calhoun (adaptation by M.Sh. Magomed-Eminov), 3) the test of effect of stress events by M. 
Khorovits IOES (Impact of the event scale in adaptation by M.Sh. Magomed-Eminov), 4) content-analysis, 5) collective type of expert estimation (Denzin, Lincoln, 2005).

\subsection{The aim of study}

Studying the bifurcation of time perspective in the emergency situation and detection of connection between time perspective transformation and fundamental conceptual intentionalities. Detection of the connection between conceptual intentionality with the peculiarities of time perspective in people with daily and non-daily experience. Comparison of conceptual intentions, temporal structure and remoteness of time perspective in people in the emergency and daily situation.

\subsection{Private hypothesis}

1) L-conceptual orientation is connected with orientation on future, at D-conceptual orientation the direction on future prevails; 2) L-conceptual direction is connected with orientation of the positive past, D-conceptual direction - with the negative past; 3) at L-conceptual direction, the structure of time (past, present, future) is characterized by completeness, and at D-conceptual - incompleteness and reduction of time structure; 4) there are differences of conceptual intentions in people in the emergency and daily situation; 5) there are differences in correlation of time components of temporal structure (representation of past, present, future) in people with extreme and daily situation; 6) there are differences in remoteness of time perspective of future in people in the emergency and daily situation.

\subsection{Test subjects}

91 subjects. Men, who served in Afghanistan (1983 - 1989). Age: 20 - 39 years old. Disability groups: I, II, III. Nationality: the Russian, Belarusian, Tatar, Kirghiz and Ukrainian people. The comparative study was conducted on three independent samples: 1) participants of military actions in Afghanistan ( $\mathrm{N}=91) ; 2$ ) military personnel - conscript-soldiers and contract soldiers before army discharge $(\mathrm{N}=113)$ with different experience of the participation in military operations in Chechnya Republic (2004-2006); 3) inhabitants of metropolitan city - people in daily situation ( $\mathrm{N}=118$ ) aged from 19-30 years old.

\subsection{Procedure}

The study was conducted on the analysis of archive data, obtained in 1989 at our participation. The modified methods of unfinished sentences consist of 13 unfinished phrases, and are applied with the purpose of study of human motivation, his motives, subjection feelings, expectations and etc. The stimulus sentences - "inductors" - are enough common and undetermined with the purpose of determination of basic conceptual intentions in test subjects, or oppositely, setting of the certain conceptual field, which represents interest for experimenter, and also minimization of social desirability factor. It is necessary to take into account that at task execution the test subjects can miss some issues or respond indifferently: "don't know", "didn't think". However, the same format of answers allow detection of so-called "problem zones" in a test person.

\section{Findings and Discussion}

The study was conducted in several stages: at first three experts conducted content-analysis of the method of unfinished sentences by categories: 1) conceptual direction (L- and D-); 2) conceptual intentions (subjective and existential senses); 3) time direction (past, present, future); further the experts conducted content-analysis of the methods of unfinished sentences according to J. Nuttin's categories; on the next stage the categories were correlated and represented in the comparative table 3.6 Supplement 3. Further the results obtained were verified in the SPSS programme. As a result of content-analysis the sample was divided in two groups: 1) test subjects with L-conceptual orientation (64.9\%), 2) test subjects with D-conceptual orientation (35.1\%).

Such answers of respondents corresponds the group of D-conceptual intentionality of direction to as "I want ... nothing"; "Sometimes it seems to me... it is impossible to execute anything and no one will help you"; "When I think about the past... then I sleep badly", "When I think about the future... I began to fear for own children"; "When I think about the sense of life... there is no it in the life". The second group (L-conceptual intentional direction) included the following 
answers: "I want... to live longer and more interesting, and visit the Southern hemisphere of Earth and see the constellation of the Southern Cross", "I dream... to live long", "Sometimes it seems to me... that I am the happiest person in the world"; "Sometimes I think... that I will change something"; "I still can... achieve the aim and become the fullfledged member of our society".

The methods themselves are directed in order to actualize the different conceptual intentions and direction on the past, present and future. However, as the qualitative analysis showed, even such issues as "When I think about the future..." or "When I think about past...", not in all respondents promoted to displaying the direction on future, building the perspective or, vice versa, retrospective analysis of "linear" time perspective, and oppositely, detected the phenomena, typical to people, which felt the emergency experience. In comparison with two conceptual orientations with time images (past, present, future) were detected: substantial connection of L-conceptual orientation and images of future $\left(X^{2}=10.563\right.$, $p<0.001)$; and substantial connection of $D$-conceptual orientation and images of future $\left(x^{2}=8.229, p<0.004\right.$.

Analysis of time direction of personality in detected opposite groups of test subjects established that there are differences between the character of time orientation at L- and D-conceptual direction: at L-conceptual direction, frequency of positive estimation of past $\left(X^{2}=19.36 ; p<0.001\right)$ and future $\left(X^{2}=43.56 ; p<0.001\right)$ is enough higher, than the negative ones, and at $D$-conceptual direction the inverse dependency is observed: the frequency of negative estimations of the past $\left(X^{2}=43.56 ; p<0.001\right)$ and present one $\left(X^{2}=17.64 ; p<0.001\right)$ in accordance with the figure 2 . In relation to the negative future in the group with $\mathrm{D}$-conceptual direction there is analogous tendency, however, substantial differences were not detected.

The time perspective at L-conceptual direction is displayed in more complete structure of time modus (past, present, future), than in D-conceptual direction, characterized by the reduction of its complete form to the separate modus of time. Let's state such answers: "Sometimes I think... that, I am their"; "Sometimes I think... about future"; "I don't want... to think more about Afghanistan", "When I think about future... I don't know, if I have one. May be, I shall not live till that days". Correlation of separated basic conceptual intentions: L- and D- with categories of motivational inductors by J. Nuttin allowed "filling" the general basic categories with more concrete subcategories, which detail and explain these sense intentions. Thus, in the emergency situation the time perspective already is not linear perspective, pragmatically determined by the objects of achievement or avoidance, but is radically decomposed, acquires binary decomposition, as it is institutionalized on the assumption from L- and D-senses: decomposition takes place on the death-centred and lifeoriented perspective).

\section{The Procedure of Comparative Study and its Results}

For detection of the conceptual intentions the methods of unfinished sentences for the control of stress and traumatic experiences in test subjects of 2 and 3 sample (military men and people on daily situation), the test of stress event estimation by Horowitz M.J., 1986) were used. The results of sample generally according to the traumatic displays evidence are correlated with the low boundary of the stress event effect force (obtained on the sample of people with high degree of evidence of traumatic experience). Therefore, we can relate test subjects to the category of people, which are in the daily situation. We considered L-conceptual and D-conceptual directions and conceptual intention as the key categories of content-analysis: subjective (material, proprietary) and existential (spiritual) senses. As the time direction, the representation of past, future, present images was studied. For detection of differences of conceptual internationalities and time perspectives, the statistical criterion by Pearson's chi-square was applied.

For detection of peculiarities of conceptual intentionality in daily and emergency situation, the correlation of respondents' expressions, which related to life-centred and death-centred directions, was analyzed. According, for each test subject the leading conceptual intentionality was determined. The obtained results evidence that decomposition of conceptual intentionality is typical only for the first group, which is composed of the test subjects with emergency experience - veterans of war in Afghanistan. For conscript-soldiers and contract, and also for test subjects in the daily life, the similar decomposition is not typical.

The analysis of the results is confirmed by substantiation of the conceptual model of time perspective offered by us. The substantial differences of conceptual intentionality between the first group (veterans of Afghanistan), on the one part, and military personnel in "hot spots" and people in daily situation, on the other part, were detected (Table 1). 
Table 1. Comparison of conceptual internationalities in 3 groups: 1) Afghanistan veterans, 2) military personnel, which finish service in Chechnya; 3) people in daily situation.

\begin{tabular}{|l|c|c|}
\hline Group & L- senses & D-senses \\
\hline Afghanistan veterans & $57 \%$ & $43 \%$ \\
\hline military personnel, which finish service in the army & $76 \%$ & $24 \%$ \\
\hline people in daily situation & $74 \%$ & $26 \%$ \\
\hline
\end{tabular}

Thus, the correlation of L- and D-conceptual direction $(p<0.05)$; existential and subject senses (accordingly, between veterans and military personnel $\left(X^{2}=13.7, p<0.001\right)$ and $\left(X^{2}=17.09, p<0.001\right)$; between veterans and people in daily situation $\left(x^{2}=23.7, p<0.001\right)$ and $\left(x^{2}=24.2, p<0.001\right)($ Table 6,7$)$ is substantially distinguished.

Table 2. Correlation of the subjective and existential senses in daily and emergency situation

\begin{tabular}{|l|c|c|}
\hline Group & Subjective senses & Existential senses \\
\hline Afghanistan veterans & $25 \%$ & $75 \%$ \\
\hline military personnel, which finish service in the army & $64 \%$ & $36 \%$ \\
\hline people in daily situation & $74 \%$ & $26 \%$ \\
\hline
\end{tabular}

Table 3. The comparison of the subjective and existential senses in daily and emergency situation according to Pearson's criterion

\begin{tabular}{|c|c|c|}
\hline Group & Subjective senses $\chi^{2}$ & Existential senses $\chi^{2}$ \\
\hline Afghanistan veterans and people in daily situation & 24.25 ** & 23.77 ** \\
\hline Afghanistan veterans and military personnel, which finish service in the army & $17.09 * \star$ & $13.70^{\star *}$ \\
\hline military personnel, which finish service in the army and people in daily situation & 0.725 & 1.613 \\
\hline
\end{tabular}

** at $p<0.000$

In people, which survived emergency situation ("Afghanistan veterans"), the high frequency of conceptual intentions of existential character, and in people with daily experience the subjective senses prevail. The substantial differences on the frequency of conceptual intentionality at comparison of samples of military personnel and people in daily situation were not observed. Correlation of temporal constituents (past and future) in the test subjects, which survive the emergency situation (veterans), is substantially distinguished with the temporal structure of people with daily experience and military personnel accordingly $(p<0.05)$ : as opposed from more valuable picture of temporality in people, which have emergency experience (both past, present and future are represented in the expressions), in the group of people with daily experience more typical orientation on future, and in lesser extent - on present, and past is almost not represented. At the same time in the first group the past, present of and future are represented more completely, than in the second and third groups, where past is reduced $($ Table 4,5$)$.

Table 4. Correlation of the time modus in daily and emergency situation

\begin{tabular}{|l|c|c|c|}
\hline Groups & past & presence & Future \\
\hline Afghanistan veterans & $42 \%$ & $37 \%$ & $21 \%$ \\
\hline military personnel, which finish the service in Chechnya & $4 \%$ & $49 \%$ & $37 \%$ \\
\hline people in daily situation & $3 \%$ & $52 \%$ & $45 \%$ \\
\hline
\end{tabular}

Table 5. Comparison of the time modus in the daily and emergency situation

\begin{tabular}{|l|c|c|c|}
\hline Group & past $\chi^{2}$ & present $\chi^{2}$ & future $\chi^{2}$ \\
\hline Afghanistan veterans and people in daily situation & $33.80^{* \star}$ & 2.52 & $8.727^{*}$ \\
\hline Afghanistan veterans and military personnel, which finish the service in Chechnya & $31.39^{\star \star}$ & 1.67 & $9.941^{*}$ \\
\hline military personnel, which finish service in Chechnya and people in daily situation & 0.143 & 0.089 & 0.43 \\
\hline
\end{tabular}

The qualitative analysis shows that the conceptual structure in military personnel, which waited army discharge in the 
moment of study, is shifted into the daily conceptual structure. The typical feeling discovered in the expressions "at home, at home..." evidence that they are affected by motivational gradient of the way out. Thus, the experience of the extreme character for these people is determined not only by the fact of presence in similar situation. The frequency of "finiteness" remembering (including, expressions about death) is substantially higher in people in the emergency situation $(p<0.05)$.

\section{Concluding Remarks}

The conducted empirical study shows that time perspective in the emergency situation is institutionalized from two temporal regions (sources) of personality life world. The conceptual intentionality in the emergency situation transforms time perspective. The time perspective is institutionalized bimodally as L-conceptual and D-conceptual directions. At Lconceptual orientation, a human is more directed in future; vice versa, at D-conceptual orientation, the direction on future is minimized and direction on the past prevails. People, who most widely and completely are directed on the present, more successfully adapt to the extreme situation, moreover, we can observe the personal growth and posttraumatic growth in them. Thus, the time perspective in the emergency situation is characterized, on the one part, by continuality, connected with L-conceptual structures of life world, on the other part - discretion, connected with D-conceptual structures of the life world. These results allow affirming that construction of time structure and temporal experience in the work of personality lies behind reproduction: personality constructs and reconstructs his life experience, instead of its simple remembering as the frozen print in the memory. In the emergency situation, the predominance of emergency sense is observed, while in the daily situation, the subjective senses are represented more. We'll state that the data obtained show also the high level of existential senses and in the daily modus that can be connected with high level of daily extreme character, and also with that test subjects are presently in the crisis transition situation.

\section{References}

Antonovsky, A. (1987). Unraveling the mystery of health: how people manage stress and stay well. San Francisco: Jossey-Bass. 238.

Bonanno, G. et al. (2005). Resilience to Loss in Bereaved Spouses, Bereaved Parents, and Bereaved Gay Men. Journal of Personality and Social Psychology. vol.88, 5. pp. 827-843.

Contrada, R., Baum, A. (2010). The handbook of stress science: biology, psychology, and health. 900.

Dalglaish, T. (2004). Cognitive Approaches to Posstraumatic Stress Disorder. The Evolution of Multirepresentational Theoretizing. Psychological Bull. vol. 130. Nr. 2. pp. 228-260.

Denzin, N., Lincoln, Y. (2005). The sage handbook of qualitative research: 3-d edition. 1210.

Foa, E., Keane, T., Friedman, M. (2009). Effective Treatments for PTSD: Practice Guidelines from International Society for traumatic stress studies. 2-d ed. NY.: Guilford press. 643.

Folkman, S. (2008). The case for positive emotions in the stress process. Anxiety Stress Coping. Jan; vol. 21(1). pp. 3-14

Herman, J. (1997). Trauma and recovery. N.Y.: Basic books. 290.

Horowitz, M. (1986). Stress response syndromes. 2nd.ed. New York: Jason Aronson. 358.

Gjesme, T. (1996). Future-time Orientation and Motivation. Advances in Motivation. - Oslo - Stockholm - Copengagen - Oxford Boston: Scandinavian University Press. 210-222.

Janoff-Bulman, R., Frantz, C. (1997). The impact of trauma on meaning: From meaningless world to meaningful life. The transformation of meaning in psychological therapies. London: Wiley. 91-106.

Kobasa, S., Maddi, S., Kahn, S. (1982). Hardiness and health: A prospective study. Jornal of Personality and Social Psychology. vol.42. pp. 164-170.

Kvassova, O. (2012). Time Perspective in Psychic Trauma. International Journal of Psychology. vol. 47. Published: Psychology Press, East Sussex, England.

Lazarus, R., Folkman, S. (1984). Stress, Appraisal and Coping. New York: Springer.

Magomed-Eminov, M.S. (1997). Post-traumatic stress disorders as a loss of meaning of life. States of mind. Oxford University Press. pp. 238-250.

Nuttin, J., Lens, W. (1985). Future time perspective and motivation: Theory and research method. Leuven University Press \& Erlbaum.

Patton, G., Coffey, C., Posterino, M, Carlin, J., Bowes, G. (2003). Life events and early onset depression: cause or consequence? Psychol. Med. vol.33. pp. 1203-1210.

Savina, O. (2012). Study of identity typology in modern adolescents and young adults. International Journal of Psychology, vol. 47. Published: Psychology Press, East Sussex, England. p. 256.

DOI: $10.1080 / 00207594.2012 .709096$

Seligman, M., Csikszentmihalyi, M. (2000). Positive Psychology: An Introduction. American Psychologist. vol.1 (55). pp. 5-14.

Selye, H. (1956). The stress of life. N.Y. 516.

Tedeschi, R., \& Calhoun, L. (2004). Posttraumatic growth: Conceptual foundation and dence. Psychological Inquiry. vol.15(1). pp. 1-18.

Zimbardo, P., Sword, R. (2012). Overcome PTSD with new psychology of time perspective therapy. N.Y.: Willey. $310 \mathrm{p}$

Wilson, J., Krauss, G. (1985). Predicting PTSD among Vietnam veterans. Post-traumatic stress disorder and the war veteran patient. 
Ed. by W.E. Kelly. N.Y. pp. 102-147

Kvassova, O. (2013). Transformation of personality time perspective in the emergency situation: abstr. of diss. ... of psychol. sc. cand. M. 34.

Magomed-Eminov, M. (2014). Ontological conceptualization of extremality phenomenon. Vestnik of Moscow University. Series 14. Psychology. No.3. pp. 79-91.

Magomed-Eminov, M.(2008). Phenomena of extremality. M.: Psychoanalytical Association. 218.

Magomed-Eminov, M. (2007). Positive psychology of a human. In 2 vv. M.: PARF.

Magomed-Eminov, M. (2014). Analysis of modern psychological trauma models from the aspect of cultural-active paradigm. Theory and practice of public development. No. 17. pp. 225-230. 
